\title{
CT Scan Evaluation of Prevalence of Paradoxical Middle Turbinate In Adult Population of Bihar
}

\author{
Raag Reeti', Md Jawed Akhtar', Avanish Kumar ${ }^{3}$, Binod Kumar4, Rajiv Ranjan Sinha ${ }^{4}$ \\ ${ }^{1}$ Tutor,Department of Anatomy, Indira Gandhi Institute of Medical Sciences, Patna, Bihar, India, ${ }^{2}$ Assistant Professor, Department of Anatomy, Indira \\ Gandhi Institute of Medical Sciences, Patna, Bihar, India, ${ }^{3}$ Professor and Head,Department of Anatomy, Indira Gandhi Institute of Medical Sciences, \\ Patna, Bihar, India, ${ }^{4}$ Additional Professor, Department of Anatomy, Indira Gandhi Institute of Medical Sciences, Patna, Bihar, India.
}

\section{Abstract}

\begin{abstract}
Introduction: Middle turbinate overlying the middle meatus is the most important anatomic area in the lateral wall of the nose. It is a thin sheet of bone which curves in different planes very similar to a dried leaf. Paradoxical Middle Turbinate (PMT) is the abnormal curvature of middle turbinate, where the convex surface faces laterally instead of its usual medial curvature and may block the drainage pathway of middle meatus. The present study aimed at observing the prevalence of the paradoxical middle turbinate in the adult population of Bihar. Subjects and Methods: This was a retrospective study being conducted on 150 patients who presented to the Department of Radiodiagnosis. Their CT scans were analysed for the presence of paradoxical middle turbinate. The results were analysed as percentage and 'p' value was calculated using Fischer's Exact Test. Results: Prevalence of Paradoxical Middle Turbinate was observed in 28 cases i.e. $18.6 \%$ cases; 16 in males and 12 in females. 'p' value was 0.677 on applying Fisher's Exact test. Conclusion: Anatomical variations of the paranasal sinus region like paradoxical middle turbinate are quite common cause of diseases involving paranasal sinuses and they must be searched for by the surgeons planning any endoscopic sinus surgery. This study attempted to provide the prevalence of the paradoxical middle turbinate which will definitely help the FESS surgery and its outcomes.
\end{abstract}

Keywords: Paradoxical middle turbinate, Paranasal sinus, Functional Endoscopic Sinus Surgery.

Corresponding Author: Dr. Md. Jawed Akhtar, Assistant Professor, Department of Anatomy, Indira Gandhi Institute of Medical Sciences, Patna, Bihar, India.

Email: drjawed2k@gmail.com

Received: January 2020

Accepted: January 2020

\section{Introduction}

The development and refinement of CT scans has allowed extensive assessment of paranasal sinuses which provide a guide map for surgeons to perform Functional Endoscopic Sinus Surgery (FESS). There could be a number of variations encountered in the sinus region which may alter the progression and outcome of the sino nasal complaints. The nasal cavity contains three projections of variable size, the inferior, middle and superior nasal conchae (turbinates). ${ }^{[1]}$ The conchae curve generally inferomedially, each roofing a groove, or meatus, which is open to the nasal cavity. The middle turbinate is a medial process of the ethmoidal labyrinth and may be pneumatized. It extends back to articulate with the perpendicular plate of the palatine bone. The middle conchae may also curve inferolaterally. Paradoxical middle turbinate is the abnormal curvature of middle turbinate, where the convex surface faces laterally instead of its usual medial curvature and may block the drainage pathway of middle meatus. ${ }^{[2]}$ The present study attempted to find out the prevalence of paradoxical middle turbinate in patients who have sino nasal complaints and who underwent CT scan.

\section{Subjects and Methods}

It was a descriptive observational study mainly focusing the computed tomographic scan anatomy of the paranasal sinus region to find out the prevalence of paradoxical middle turbinate. The study was conducted on sinonasal computed tomographic images of 150 patients (79 males and 71 females) which were collected from the Department of Radiology, Indira Gandhi Institute of Medical Sciences, Patna, Bihar after studying their history and complaints. The CT scans of the patients fulfilling the inclusion and exclusion criteria were collected for the study. The variations that were observed were identified and noted.

\section{Inclusion criteria}

Patients with sinonasal symptoms who underwent CT scan.

\section{Exclusion criteria}

Patients whose CT plates revealed - Nasopharyngeal tumours, polyp, any other sinonasal disease causing bony 
deformity or bony destruction, H/O previous surgeries involving nasal cavity and paranasal sinuses (as obtained from the records), H/O trauma or injury (as obtained from the records).

The scan was performed by keeping the patient in prone position. Axial sections were taken from tip of the nose to the roof of the frontal sinus. Coronal sections were taken from tip of the nose to the roof of sphenoid sinus perpendicular to the hard palate.

Prevalence of paradoxical middle turbinate was seen on the CT scans and the results were analysed as percentages. Chi Square Tests were applied to calculate the ' $p$ ' value to find out any statistically significant difference between males and females.

\section{Results}

It was observed in 28 cases; 16 in males and 12 in females.

Table 1: Gender wise comparison of normal curvature of middle turbinate and paradoxical curvature of middle turbinate

\begin{tabular}{|l|l|l|l|}
\hline Gender & $\begin{array}{l}\text { Study cases } \\
\text { with PMT }\end{array}$ & $\begin{array}{l}\text { Study cases } \\
\text { without PMT }\end{array}$ & Total \\
\hline Male & 16 & 63 & 79 \\
& $(10.67 \%)$ & $(42 \%)$ & $(52.67 \%)$ \\
\hline Female & 12 & 59 & 71 \\
& $(8 \%)$ & $(39.33 \%)$ & $(47.33 \%)$ \\
\hline Total & 28 & 122 & 150 \\
& $(18.67 \%)$ & $(81.33 \%)$ & $(100 \%)$ \\
\hline
\end{tabular}

'p' value -0.677 on applying Fisher's Exact test.

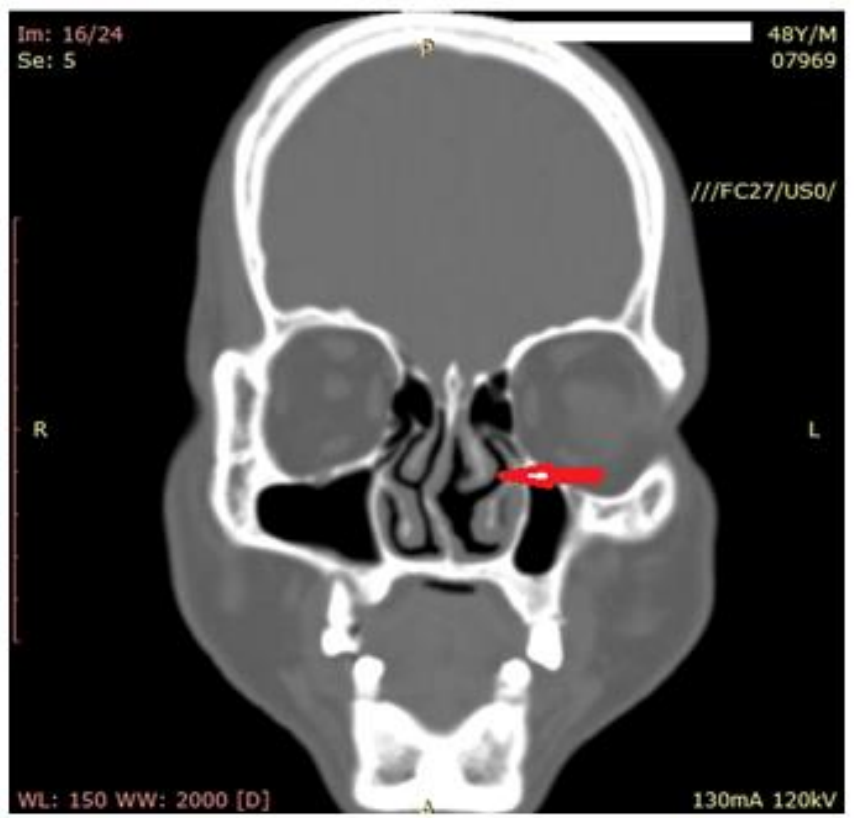

Figure 1: CT of PNS - Coronal section showing Paradoxical Middle Turbinate on left side

\section{Discussion}

Lateral convexity in the curvature of middle turbinate which is called Paradoxical was observed in $18.67 \%$ of the cases in the present study. Various studies have incorporated this parameter. Priyanko Chakraborty et al ${ }^{[3]}$ in 2016 performed a study in Department of Otorhinolaryngology, Sir Sunderlal Hospital, Banaras Hindu University, Varanasi. 82 patients were included in the study. They were diagnosed as a probable case of chronic rhinosinusitis on the basis of history and nasal endoscopy and then subjected to CT scan. Thin slice coronal, axial and sagittal films were obtained both in soft tissue window and bone window for optimum visualization of all the structures. They observed paradoxical middle turbinate in $14.63 \%$ cases. D. Krishna Chaitanya et $\mathrm{al}^{[4]}$ in 2015 conducted a study on 100 patients with suspected nasal pathology referred to Department of Radiology in Kamineni Institute of Medical Sciences, Narketpally, Andhra Pradesh. The scans were of both axial and coronal planes and noted it in $11 \%$ cases. Liu X et al ${ }^{[5]}$ in 1999 tried to find out the relation between the anatomic variations of osteomeatal complex and chronic sinusitis. They studied coronal CT scans of 297 individuals. Paradoxical curvature of the middle turbinate was in $13.97 \%$ cases. Mazza D et $\mathrm{al}^{[6]}$ in 2007 performed a 64-slice CT evaluation of some important anatomic variants of paranasal sinuses. 100 patients were selected among all those that had undergone a paranasal sinuses CT examination. They were 45 caucasian women and 55 men, all aged between 18 and 70 years, mean age 46 years. This study was conducted using a 64-slice Siemens Somatom Volume-Zoom multidetector Spiral CT. CT examination was performed through a thin axial acquisition; the patient was lying on his back and the images were processed with multiplanar reconstruction. They noted paradoxical middle turbinate in $11 \%$ cases. Perez Pinas et al ${ }^{[7]}$ in 2000 studied 110 CTs of sino nasal region of Spanish patients who were suspected to have inflammatory sinus pathology. They observed paradoxical curvature of middle turbinate in $10 \%$ cases. $\mathrm{K}$ Dua et $\mathrm{al}^{[8]}$ in 2005 studied the variations of paranasal sinus on CT scan in chronic sinusitis. 50 patients of chronic sinusitis were evaluated by CT Scan. The anatomical variations and changes in osteomeatal complex on CT Scan were studied. They observed paradoxical middle turbinate in $10 \%$ of the cases. Maru Y K et al ${ }^{[9]}$ in 2001 studied the sinonasal CT scan of 61 patients with symptoms of chronic sinusitis. According to them, paradoxical middle turbinate was noted in $11.5 \%$ cases. These results are almost corroborative with the present study. But some studies noted very low percentage of cases with paradoxical curvature of middle turbinate. Arslan et $\mathrm{al}^{[10]}$ studied the CT scans for anatomic variations of paranasal sinus in patients who had to undergo endoscopic sinus surgery for chronic rhinosinusitis. CT scans of 200 patients with chronic sinusitis were analyzed to determine the prevalence of anatomic variants. They observed paradoxical middle turbinate only in $3 \%$ of the cases. Tantilipikorn $\mathrm{P}$ et $\mathrm{al}^{[11]}$ in 2009 compared the accuracy of limited CT with the full CT as the standard evaluation for inflammatory diseases of paranasal sinus and the identification of anatomical variations. Full CT scan provided slides from both axial and coronal planes. Limited CT scan revealed slides from the coronal plane only. They used full CT as the standard, then evaluated the accuracy of limited CT for the radiologic staging of rhinosinusitis and the anatomic variations which are an important landmark for surgical operations in rhinosinusitis. They noted paradoxical 
middle turbinate in $2.27 \%$ in a population of Thailand. Kayalioglu $G$ et $\mathrm{al}^{[12]}$ in 2000 performed high resolution computed tomography images of paranasal sinuses on 82 adult patients without sinus pathology and on 90 adult patients with sinus disease and observed paradoxical curvature of the middle concha in $12.22 \%$ sinus patients and $7.31 \%$ non sinus patients. Robinson $M$ et $\mathrm{al}^{[13]}$ in 2010observed the variations in the paranasal sinuses in a non-random sample of museum skulls of Melanesians. This racial group was not previously studied in this respect. They found paradoxical middle turbinate in $7.5 \%$ cases. Nitin V Deosthale et $\mathrm{al}^{[14]}$ in 2014 conducted a cross sectional study at NKP Salve Institute of Medical Sciences, Nagpur to detect the prevalence of anatomical variations of nose and paranasal sinuses in Chronic Rhinosinusitis (CRS) on 'Nasal Endoscopy', and 'Computed Tomography' and correlated the two investigations modalities and studied association of anatomical variations of nose and paranasal sinuses in Chronic Rhinosinusitis. Diagnostic Nasal Endoscopy (DNE) and Computed Tomography of nose and Paranasal Sinuses of 122 patients of chronic rhinosinusitis were studied and results were statistically analysed using z-test and chi-square test. They observed paradoxical middle turbinate in $9.01 \%$ cases. Chandel N S et al ${ }^{[15]}$ in 2015 conducted the study in Bhopal to evaluate the anatomical variation of PNS by CT scan and compared and analyzed congenital anatomical variations of paranasal sinuses in male and female and assessed frequency of anatomical variation of PNS. All patients were included who were referred for CT scan of PNS. Paediatric ages, pregnant women, patients with history of sinonasal surgery or past history of surgery in the paranasal region were not included in the study. Anatomical variants were analyzed using a soft part window and bone density window. They observed paradoxical middle turbinate in $40.8 \%$ of the cases. Sheetal D et al ${ }^{[16]}$ in 2011 performed a study and correlated the CT findings and the endoscopic findings in FESS, the anatomical abnormalities and the mucosal changes in patients with chronic rhinosinusitis (CRS) and the reliability and validity of CT scan in the management of CRS. A time bound cross sectional study was conducted. 45 patients with CRS underwent pre-operative CT PNS, followed by FESS. According to them, paradoxical middle turbinate was observed in $25 \%$ of the cases. Ashok K Gupta et $\mathrm{al}^{[17]}$ in 2012 performed a prospective and non-randomized study. Initially a cadaveric study was performed to know the anatomical variations of PNS and their percentages in North Indian population. Then endoscopic surgery was performed on 69 patients for disease of nose and PNS. Then a noncontrast CT of nose and PNS was done and was studied for different anatomical variations. Total 138 slides were examined. Paradoxical middle turbinate was found in $1.44 \%$ patients on CT but in $13.04 \%$ during surgery. Mohammad Adeel et $\mathrm{al}^{[18]}$ in 2013 conducted a study at the Aga Khan University Hospital, Karachi, and studied computed tomography scans of 77 patients. All the scans were reviewed using Picture Archiving Communication System computer software. Paradoxical middle turbinate was observed in $14.3 \%$ cases. Thus, the variation in the curvature of the middle turbinate was present from $2 \%$ to $40 \%$ in different studies.
Table 2: Comparative table among various studies showing variation in occurrence of Paradoxical Middle Turbinate

\begin{tabular}{|c|c|}
\hline Study & \% of Paradoxical MT \\
\hline Present study & $18.67 \%$ \\
\hline Chakraborty $\mathrm{P}$ et $\mathrm{al}^{3}$ & $15.63 \%$ \\
\hline Chaitanya et $\mathrm{al}^{4}$ & $11 \%$ \\
\hline Liu $X$ et $\mathrm{al}^{5}$ & $13.97 \%$ \\
\hline Mazza D et $\mathrm{al}^{6}$ & $11 \%$ \\
\hline Perez Pinas et al ${ }^{7}$ & $10 \%$ \\
\hline K Dua et $\mathrm{al}^{8}$ & $10 \%$ \\
\hline Maru YK et $\mathrm{al}^{9}$ & $11.5 \%$ \\
\hline${\text { Arslan } \mathrm{H} \text { et } \mathrm{al}^{10}}^{10}$ & $3 \%$ \\
\hline Tantilipikorn $\mathrm{P}$ et $\mathrm{al}^{11}$ & $2.27 \%$ \\
\hline 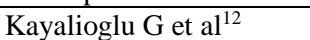 & $12.22 \%$ \\
\hline Robinson $\mathrm{M}$ et $\mathrm{al}^{13}$ & $7.5 \%$ \\
\hline Nitin V Deosthale et $\mathrm{al}^{14}$ & $9.01 \%$ \\
\hline Chandel NS et $\mathrm{al}^{15}$ & $40.8 \%$ \\
\hline Sheetal et al ${ }^{16}$ & $25 \%$ \\
\hline Ashok Gupta et al ${ }^{17}$ & $1.44 \%$ \\
\hline Mohammad Adeel et al ${ }^{18}$ & $14.3 \%$ \\
\hline
\end{tabular}

\section{Conclusion}

The present study attempted to provide the prevalence of paradoxical middle turbinate in the concerned population. This knowledge of the anatomical variation is a must for the ENT surgeon before embarking upon FESS. The surgeon can not take a single step without knowing the different types of variations because that may lead to inadvertent injury to some of the vital structures. Thus, it can be concluded that this study will provide a baseline data for the prevalence of paradoxical middle turbinate in the population of Bihar and will help the surgeons to plan for the surgery accordingly. It can also be concluded that the prevalence differs in the different parts of the country including different populations and ethnicities.

\section{References}

1. Standring S, editor in chief, Jafek BW. Gray's anatomy: the anatomical basis of clinical practice $40^{\text {th }}$ ed. Churchill Livingstone Elsevier; 2008. p. 556-559.

2. Bradoo R. Anatomical Principles of Endoscopic Sinus Surgery: A Step by Step Approach. Jaypee Brothers Medical Publishers (P) Ltd. 2007.

3. Chakraborty P, Jain RK. Radiologic variations of nose and paranasal sinuses: A CT based study. JMSCR May 2016;4(5):10536-41.

4. Chaitanya D, Suseclamma D, Singh V. Anatomical variations of paranasal air sinuses - A CT scan study. Journal of the Anatomical Society of India June 2015;64(1):87-90.

5. Liu X, Zhang G, Xu G. Anatomic variations of osteomeatal complex \& their correlation with chronic sinusitis : CT evaluation. ZhonghuaEr Bi Yan HouKeZaZhi 1999 Jun;34(3):143-6.

6. Mazza D, Bontempi E, Guerisi A, elonti S, Cipolla G, Perrone A, Lomele $\mathrm{L}$, et al. Paranasal sinuses anatomic variants : 64- slice CT evaluation. InerveStomatol 2007 Jun; 56(6):311-18.

7. Pinas IP, Sabate J, Carmona A, Catalina-Herrera CJ, Castellanos JJ. Anatomical variations in the human paranasal sinus region studied by CT. J Anat 2000 Aug;197(pt2):221-227.

8. Dua K, Chopra H, Khurana AS, Munjal M. CT scan variations in chronic sinusitis. Indian J Radiol Imaging 2005; 15:315-20.

9. Maru YK, Gupta V. Anatomic variations of the bone in sinonasal CT. Indian Journal of Otolaryngol and Head Neck Surgery 2001;53:123-28.

10. Arslan H, Aydinlioglu A, Bozkurt M, Egeli E. Anatomic 


\section{Reeti et al,CS Scan Evaluation of Prevalence of Paradaxical Middle Turlinate}

variations of the paranasal sinuses: CT examination for endoscopic sinus surgery. AurisNasus Larynx 1999 jan;26(1):3948.

11. Tantilipikorn P, Churojana A, Chiewwit P, Phuttharak W, Lerdlum S, Aeumjaturapat S, et al. The accuracy of limited CT in the evaluation of chronic rhinosinusitis and for endoscopic sinus surgery : A multicenter study. Siriraj Medical Journal 2009;61(1):3-7.

12. Kayalioglu G, Oyar O, Govsa F. Nasal cavity and paranasal sinus bony variations: a computerized tomographic study. Rhinology Sep 2000;38(3):108-13

13. Robinson M, Donlon D, Harrison H, Houang M, Stammberger H, Wolf G. Variations of the paranasal sinuses in Melanesians as observed by CT. Rhinology 2010 Mar;48(1):11-7.

14. Deosthale NV, Khadakkar SP, Singh B, Harkare VV, Dhoke PR, Dhote KS: Anatomical variations of Nose and Paranasal Sinuses in Chronic Rhinosinusitis. People's Journal of Scientific Research 2014;7(2):1-7.

15. Chandel NS, Gupta R, Vyas MM. Computerized Tomographic Evaluation of Anatomical Variations of Paranasal Sinus \& Nose. National Journal of Medical \& Dental Research Oct- Dec 2015;4(1):48-72.

16. Sheetal D, Devan PP, Manjunath P, Martin P, Satish K, Sreekantha, Satish TG, et al. CT PNS : Do we really require before FESS? J ClinDiag Res 2011;5(2):179-81.

17. Gupta AK, Gupta B, Gupta N, Tripathi N. Computerized Tomography of Paranasal Sinuses: A Roadmap to Endoscopic Surgery. ClinRhinolInt J 2012;5(1):1-10.

18. Adeel M, Rajput M S, Akhtar S, Ikram M, Arain A, Khattak YJ. Anatomical variations of nose and paranasal sinuses: CT scan review. J Pak Med Assoc 2013 Mar;63(3):317-9.

Copyright: (C) the author(s), 2020. It is an open-access article distributed under the terms of the Creative Commons Attribution License (CC BY 4.0), which permits authors to retain ownership of the copyright for their content, and allow anyone to download, reuse, reprint, modify, distribute and/or copy the content as long as the original authors and source are cited.

How to cite this article: Reeti R, Akhtar MJ, Kumar A, Kumar B, Sinha RR. CT Scan Evaluation of Prevalence of Paradoxical Middle Turbinate In Adult Population of Bihar. Acad. Anat. Int. 2020;6(1):01-04.

DOI: dx.doi.org/10.21276/aanat.2020.6.1.1

Source of Support: Nil, Conflict of Interest: None declared. 